\title{
Palms for North Florida ${ }^{1}$
}

\section{Edwin R. Duke and Gary W. Knox ${ }^{2}$}

Palm (päm) n. Any of various chiefly tropical evergreen trees, shrubs or woody vines of the family Palmae (Arecaceae), having unbranched trunks with a crown of pinnate or palmate leaves having conspicuous parallel venation. $[\mathrm{ME}<\mathrm{OE}<\mathrm{OFr}$. Palme, both < Latin palma, palm of the hand.] American Heritage College Dictionary, $3^{\text {rd }}$ ed.

Palms are a prominent part of the Florida landscape. While many of the palms used in the southern parts of the state are not cold hardy, there is still a good selection of palm species that will grow in more northern regions (Figure 1).

\section{Predicting Cold Hardiness in Palms}

Palms suitable for northern Florida must be able to withstand at least intermittent periods of below-freezing weather. It is difficult to make generalizations about the cold hardiness of palms. Different growers report different experiences with the same species of palm after a cold spell. The reasons for this are numerous - the nature of the cold spell itself, microclimate differences surrounding the palm, and the palms themselves.

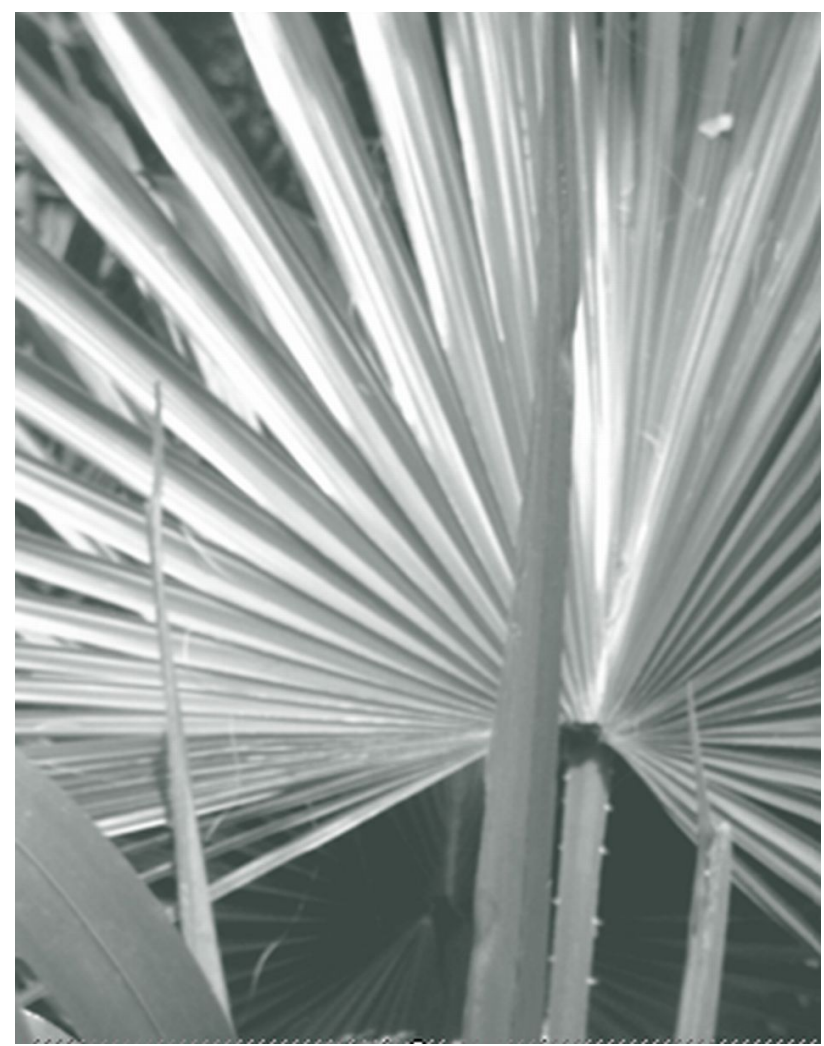

Figure 1. Chinese Fam Palm, Livistona chinensis is one of many cold hardy palms. Note spines on the leaf petiole.

A cold spell can come on slowly or quickly. It is generally thought that a gradual cooling allows plants to acclimate or "harden off." The length of time and

1. This document is ENH1094, one of a series of the Environmental Horticulture Department, Florida Cooperative Extension Service, Institute of Food and Agricultural Sciences, University of Florida. Original publication date February 2008. Visit the EDIS Web Site at http://edis.ifas.ufl.edu.

2. Edwin R. Duke, Associate Professor, Ornamental Horticulture and Landscape Design and Management, Florida A\&M University, College of Engineering Sciences, Technology and Agriculture, 306 Perry-Paige South, Tallahassee, FL 32307; and Gary W. Knox, Extension Specialist and Professor of Environmental Horticulture, University of Florida/IFAS, North Florida Research and Education Center, 155 Research Road, Quincy, FL 32351. 
depth of hard freeze, wind speed, and relative humidity can also influence how destructive a cold spell might be.

Microclimates surrounding a particular plant can influence whether or not a palm will survive a particular cold spell. A plant sheltered by a building or other plants is more likely to survive than one that is exposed. The elevation of a location can also be a factor in a plant's survival-cold air tends to accumulate in low-lying areas.

Finally, how successfully a palm can withstand cold is determined by the palm itself. Its age, height, hereditary differences selected out over time by environmental influences in its native habitat, and the overall health of the palm all have an effect on a plant's survival of many environmental conditions, including cold.

It would seem simple to predict a palm's cold hardiness by looking at a few variables regarding the palm's native habitat-is the palm native to the cooler northern or southern latitudes rather than nearer the equator? Is the palm native to higher altitudes? -however, some tropical species have been found to be somewhat hardy.

Perhaps the best indicator of the potential cold hardiness of a palm is its ability to withstand drought. Many of the more cold tolerant palms come from regions with distinct wet and dry seasons. Freezing stress for any plant is in many ways similar to drought stress, at both the whole-plant and the cellular level-freezing temperatures prevent or reduce the uptake and translocation of water. Tropical or subtropical palms that are adapted to survive the stress of low water conditions (no matter what conditions - cold or drought - are causing it) will have a better chance of surviving cold temperatures. Palms that grow in semi-arid areas, savannas, exposed sandy coastal zones, and on exposed well-drained rocky outcrops are prime candidates for testing in colder climates.

\section{Growing Conditions for Palms}

In many ways, the growing conditions of Florida are ideal for growing palms. Our hot, wet summers and cool, dry winters (relatively speaking) are ideal for the growth of most (but not all) species of palms. In addition, much of Florida is covered with sandy soils underlain by limestone, both of which are conducive to the growth of many palms. The heavier, clay soils found in limited regions of northwest Florida may be made more suitable for the growth of desert-adapted palms by the addition of sand or perlite to 'lighten" the soil. In addition, planting the palm in a raised berm may improve the palm's chance of survival.

\section{Maintenance of Palms}

Palms are not particularly high maintenance plants, but their care must not be neglected. In Florida, the season for rapid growth coincides with the arrival of high temperatures $\left(80^{\circ} \mathrm{F}\right.$ or more). It is during that time that maintenance is most important.

\section{Mineral Nutrition}

Palms suffer quickly and conspicuously from improper mineral nutrition. The problems may arise from either insufficient or improper fertilization.

Potassium (K) deficiency is perhaps the most widespread and serious nutritional problem of palms. Florida's sandy soils have a poor ability to retain nutrients. This factor combined with heavy rainfall make Florida's soil low in potassium content.

Symptoms of potassium deficiency vary among palm species but typically begin with translucent yellow or orange "freckles" on the leaflets of the oldest leaves. As the symptoms progress, the freckles may be accompanied by necrotic (dead tissue) lesions. Further progression of the deficiency results in marginal necrosis of the leaflets. The leaflets or entire fronds may become withered or frizzled in appearance.

The first response of most gardeners to partial necrosis of leaves is to prune off the "offending" frond. Rather than helping, this actually worsens the problem by preventing the palm from translocating the remaining potassium to the plant's growing point. 
Magnesium $(\mathrm{Mg}$ ) deficiency is also quite common, especially on date palm (Phoenix species). Typical symptoms include a broad band of chlorotic (yellow) tissue along the margin of the older leaves. The center of the leaf remains green. As with potassium deficiency, leaves exhibiting magnesium deficiency should not be removed until they are dead in order to allow the remaining magnesium to be moved to the newer leaves.

Prevention is the key to both potassium and magnesium deficiency. Once symptoms appear, they cannot be reversed. Some "palm special" fertilizers are specially formulated to contain elevated (and balanced) levels of potassium and magnesium, as well as nitrogen, in a controlled-release form.

Iron $(\mathrm{Fe})$ deficiency sometimes occurs in palms in the growing season following a cold winter or in palms growing in poorly aerated soils. Cold temperatures may induce nutrient deficiency by slowing or preventing nutrient uptake. Waterlogged soil effectively suffocates the roots, also preventing nutrient uptake. Iron deficiency appears first on the newest leaves and is characterized by yellowing between leaf veins.

Iron deficiency symptoms may be alleviated by foliar application of iron chelate. This is especially effective for symptoms caused by transient cold spells. However, long term correction of symptoms due to poor soil conditions is best achieved by changing soil conditions.

For more detailed information on palm nutrition, refer to IFAS publications, Nutrient Deficiencies of Landscape and Field-Grown Palms in Florida, and Fertilization of Field-grown ${ }^{a}$ and Landscape Palms in Florida ${ }^{b}$.

\section{Irrigation}

Most palms tolerate some drought. However, it is a good idea to keep palms well-watered during the active growing period. Keep in mind that "well-watered" does not mean waterlogged. Damage of roots due to waterlogging may induce certain nutrient deficiencies and allow infection by pathogenic fungi or bacteria.
The cooler winter months coincide with periods of slower growth. During this time, most palms, but especially those from desert areas, do best with reduced irrigation.

\section{Insects and Diseases}

As a group, palms are fairly resistant to pests and diseases. This does not mean, however, that they are pest-free. Certain insects and diseases have proven especially devastating for palms.

Palms are not immune to common pests such as caterpillars, aphids, scales, and spider mites. These pests may be controlled by conventional means.

A not-so-common problem for many palms is the palmetto weevil (Rhynchophorus cruentatus). This weevil is attracted to stressed palms, especially during or after transplanting. The adult female deposits her eggs near the crown of the plant, and the resulting larvae tunnel through the tender meristem tissue. Death of the meristem results in the death of the entire palm.

Prevention by reducing stress to the palm is the best method to control the palmetto weevil. The practice of removing the majority of the fronds and roots of a palm during transplanting is one method to reduce transplant stress. For more information, refer to Palmetto Weevil, 'Rhynchophorus cruentatus' ${ }^{\mathrm{c}}$.

Several fungal diseases have proven especially damaging to certain palms. Ganoderma, Fusarium, Phytophthora, and Thielaviopsis are fungi that cause diseases that may result in the death of affected palms see IFAS publications Ganoderma Butt Rot of Palms ${ }^{\mathrm{d}}$; Fusarium Wilt of Canary Island Date Palm ${ }^{\mathrm{e}}$; Thielaviopsis Trunk Rot of Palm ${ }^{\mathrm{f}}$; and Bud Rots of Palm $^{\mathrm{g}}$. Additional information on diseases may be found in Leaf Spots and Leaf Blights of Palm ${ }^{\mathrm{h}}$.

A number of conditions resembling pest damage may be caused by environmental factors. For more information, refer to IFAS publication Physiological Disorders of Landscape Palms ${ }^{\mathrm{i}}$. 


\section{Pruning}

Like all plants, palms benefit from regular pruning. Ideally, pruning of palms should be limited to removing dead fronds. Practically, this is not always acceptable. When fronds with living tissue need to be pruned, remove only the lower fronds extending out less than 90 degrees from the trunk.

New growth should never be pruned. The natural growth habit of palms does not allow them to be maintained at a constant height.

\section{Treating Cold Damaged Palms}

Even with the best of care, palms growing in northern Florida are going to experience temperatures below those that they can tolerate without damage.

\section{Effects of Cold Temperatures}

Cold weather affects palms in several ways. Growth of the apical bud is reduced, and growth of roots is slowed. This reduced activity often weakens the palm to the point that diseases may become active and kill the palm.

Severe cold damage caused by frost or below-freezing temperatures may destroy plant tissues. Due to the nature of the water-conducting tissue in palms, the destruction of stem tissue may severely reduce water conduction for years. As warmer weather returns, plant pathogens, whether primary or secondary, may attack weakened plants through damaged tissue.

\section{After a Freeze}

After a palm experiences damaging temperatures, it is important to protect the growing point until active growth resumes.

Carefully inspect the damaged fronds before pruning. Leaves should not be removed if they still contain viable green tissue. The green portions of leaves are important for adequate production of sugars from photosynthesis. Allowing the leaves to die naturally allows the nutrients remaining in the leaf to be translocated to other areas where they are needed.
Immediately after pruning away dead tissue, spray the palm with a fungicide; copper-containing fungicides often are recommended. This will reduce the level of potentially pathogenic bacteria and fungi. Repeat the fungicide spray as recommended by the fungicide label or about 10 days after the first treatment. Make sure that these sprays cover the damaged tissue and the bud thoroughly. If the fungicide contains copper, do not repeat the sprays more than twice so as to avoid possible copper toxicity. If the soil has frozen, a soil drench of a combination of a broad-spectrum and a water mold-specific fungicide may suppress root diseases.

Freeze damage to the palm's vascular tissue in the trunk may limit the ability of the plant to supply water to the canopy. Unlike typical trees, palms do not have the ability to regenerate vascular tissue within the trunk. A sudden collapse of some (or all) of the leaves during the first periods of high temperatures in the spring or summer following a damaging winter freeze may indicate this type of trunk damage. Unfortunately, there is nothing that can be done at this point. Loss of the palm is likely inevitable.

\section{Palm Selection}

An important factor to consider when selecting a palm for a particular area is the average minimum temperature that can be expected. The US Department of Agriculture has used historical climatic data to divide the country into climate zones. Each zone represents a $10^{\circ} \mathrm{F}$ range. Most of northern Florida can be placed in one of two USDA climate zones. Extreme northern parts of the state are placed in the lower half of USDA zone $8\left(10^{\circ}-19^{\circ} \mathrm{F}\right)$, meaning that the average minimum temperature that may be expected is $15^{\circ} \mathrm{F}$. Coastal regions of the northern Florida are typically in the upper half of zone $9\left(20^{\circ}-29^{\circ} \mathrm{F}\right)$, meaning that the average minimum temperature that may be expected is $20^{\circ} \mathrm{F}$. Of course these are only average lows. Single digit lows have been recorded several times in the last 100 years.

The table in this publication includes palms exhibiting some degree of cold hardiness. In addition to cold hardiness, intended use and characteristics of 
the site should be used as selection criteria. Careful study of the list of palms and their characteristics will allow selection of the right palm for the landscape situation.

\section{Availability}

Palms are increasingly appreciated by consumers. Cold hardy palms are in great demand and the nursery industry is responding with additional production. Currently, palms that are most widely available are in the genera Butia (pindo palm), Chamaedorea (parlor palm), Livistona (fan palm), Phoenix (date palm), Rhapidophyllum (needle palm), Rhapis (lady palm), Sabal (palmetto), Serenoa (saw palmetto), Syagrus (queen palm), Trachycarpus (windmill palm), and Washingtonia (washington palm; Figure 2). Refer to Table 1 for specific species and their cold hardiness information. Other cold hardy palms may be found at better garden centers and specialty nurseries.

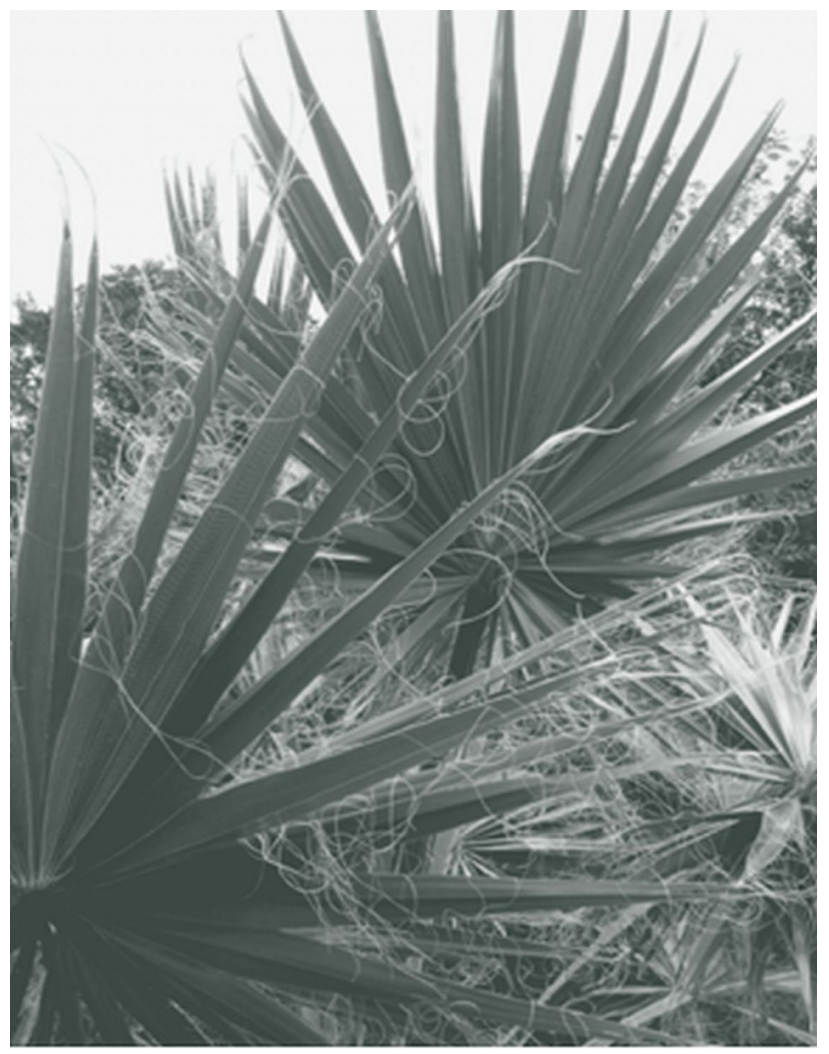

Figure 2. Washingtonia filifera leaves - note filaments hanging from leaf margins.

\section{Endnotes}

${ }^{a}$ Nutrient Deficiencies of Landscape and Field-Grown Palms in Florida, ILN\# ENH1018 / DLN\# EP273 (http://edis.ifas.ufl.edu/EP273)

${ }^{\mathrm{b}}$ Fertilization of Field-grown and Landscape Palms in Florida, ILN\# ENH1009 / DLN\# EP261 (http://edis.ifas.ufl.edu/EP261)

c Palmetto Weevil, Rhynchophorus cruentatus, ILN\# EENY013 / DLN\# IN139

(http://edis.ifas.ufl.edu/IN139)

${ }^{\mathrm{d}}$ Ganoderma Butt Rot of Palms, ILN\# PP54 / DLN\# PP100 (http://edis.ifas.ufl.edu/PP100)

${ }^{\mathrm{e}}$ Fusarium Wilt of Canary Island Date Palm, ILN\# PP215 / DLN\# PP139 (http://edis.ifas.ufl.edu/PP139)

${ }^{f}$ Thielaviopsis Trunk Rot of Palm, ILN\# PP219/ DLN\# PP143 (http://edis.ifas.ufl.edu/PP143)

g Bud Rots of Palm, ILN\# PP220 / DLN\# PP144 (http://edis.ifas.ufl.edu/PP144)

h Leaf Spots and Leaf Blights of Palm, ILN\# PP218 / DLN\# PP142 (http://edis.ifas.ufl.edu/PP142)

${ }^{\mathrm{i}}$ Physiological Disorders of Landscape Palms, ILN\# ENH1011 / DLN\# EP263

(http://edis.ifas.ufl.edu/EP263)

\section{References}

Fox, A.M., D.R. Gordon, J.A. Dusky, L. Tyson, and R.K. Stocker. 2005. IFAS Assessment of the Status of Non-Native Plants in Florida's Natural Areas. http://plants.ifas.ufl.edu/assessment/ (Accessed 28 August 2007).

Gilman, E.F. 2006. Palms in the Landscape. http://hort.ifas.ufl.edu/woody/palms.html (Accessed 28 August 2007).

McClendon, T., W. Roberds and J. LeVert. 2007. Hardy Palms for the Southeast. Southeastern Palm Society, Inc., Apison, TN. 140 pp.

Southeastern Palm Society. 2007. Hardy Palms: A Quick Reference. http://www.sepalms.org/Hardy\%20Palms/ 
SPS_Hardy_Palms_A_Quick_Reference.htm (Accessed 28 August 2007).

University of Florida/IFAS Fort Lauderdale REC faculty and staff. 2007. Palm Production \&

Maintenance.

http://flrec.ifas.ufl.edu/palm_prod/

palm_production.shtml (Accessed 28 August 2007). 
Table 1. Palms for northern Florida and their associated characteristics ${ }^{3}$.

\begin{tabular}{|c|c|c|c|c|c|c|c|c|c|c|c|c|}
\hline $\begin{array}{l}\text { Scientific } \\
\text { Name }\end{array}$ & $\begin{array}{l}\text { Common } \\
\text { Name }\end{array}$ & Origin & $\begin{array}{l}\text { Native } \\
\text { Habitat }\end{array}$ & $\begin{array}{l}\text { Hardines } \\
\text { s Zone }\end{array}$ & $\begin{array}{l}\text { Typical } \\
\text { Height }\end{array}$ & $\begin{array}{l}\text { Growth } \\
\text { Rate }\end{array}$ & Habit & Light & $\begin{array}{l}\text { Salt } \\
\text { Tolerance } \\
\end{array}$ & $\begin{array}{l}\text { Leaf } \\
\text { Type }\end{array}$ & $\begin{array}{l}\text { Foliage } \\
\text { Color }\end{array}$ & Comments \\
\hline $\begin{array}{l}\text { Acoelorrhaphe } \\
\text { wrightii }\end{array}$ & $\begin{array}{l}\text { Paurotis } \\
\text { palm, } \\
\text { Everglades } \\
\text { palm }\end{array}$ & $\begin{array}{l}\text { Southern } \\
\text { Florida, } \\
\text { Caribbean } \\
\text { region }\end{array}$ & $\begin{array}{l}\text { Moist, } \\
\text { swamp- } \\
\text { like } \\
\text { regions }\end{array}$ & $\begin{array}{l}9 a-11 \\
23^{\circ} \mathrm{F}\end{array}$ & $20^{\prime}$ & $\begin{array}{l}\text { Slow to } \\
\text { moderate }\end{array}$ & Clustering & $\begin{array}{l}\text { Partial } \\
\text { shade } \\
\text { to full } \\
\text { sun }\end{array}$ & Moderate & Palmate & $\begin{array}{l}\text { Green, } \\
\text { silvery- } \\
\text { green } \\
\text { below }\end{array}$ & $\begin{array}{l}\text { Native to the } \\
\text { Florida } \\
\text { Everglades. } \\
\text { Adaptable to drier } \\
\text { soils. Reported to } \\
\text { tolerate } 19^{\circ} \mathrm{F} \text {. }\end{array}$ \\
\hline Arenga engleri & $\begin{array}{l}\text { Dwarf } \\
\text { sugar palm }\end{array}$ & $\begin{array}{l}\text { Taiwan, } \\
\text { Ryukyu } \\
\text { Islands }\end{array}$ & $\begin{array}{l}\text { Open } \\
\text { forests }\end{array}$ & $\begin{array}{l}9 a-11 \\
23^{\circ} \mathrm{F}\end{array}$ & $6-8^{\prime}$ & $\begin{array}{l}\text { Slow to } \\
\text { moderate }\end{array}$ & Clustering & $\begin{array}{l}\text { Partial } \\
\text { shade } \\
\text { to full } \\
\text { sun }\end{array}$ & Low & Pinnate & $\begin{array}{l}\text { Dark } \\
\text { green } \\
\text { above, } \\
\text { silvery } \\
\text { below } \\
\end{array}$ & $\begin{array}{l}\text { Fiber-covered } \\
\text { stems. Fruit } \\
\text { contain irritating } \\
\text { calcium oxylate } \\
\text { crystals. }\end{array}$ \\
\hline Brahea armata & $\begin{array}{l}\text { Blue } \\
\text { hesper } \\
\text { palm }\end{array}$ & $\begin{array}{l}\text { Mexico, } \\
\text { southern } \\
\text { California }\end{array}$ & $\begin{array}{l}\text { Arid, } \\
\text { desert } \\
\text { regions }\end{array}$ & $\begin{array}{l}8 \mathrm{a}-10 \\
14^{\circ} \mathrm{F}\end{array}$ & $\begin{array}{l}30-40 ' \\
4-8 \text { in } \\
F L\end{array}$ & Slow & Solitary & Full sun & Moderate & $\begin{array}{l}\text { Costa- } \\
\text { palmate }\end{array}$ & $\begin{array}{l}\text { Blue- } \\
\text { green, } \\
\text { waxy }\end{array}$ & $\begin{array}{l}\text { Does not like high } \\
\text { humidity. Requires } \\
\text { well-drained soil. }\end{array}$ \\
\hline Butia capitata & $\begin{array}{l}\text { Pindo } \\
\text { palm, jelly } \\
\text { palm }\end{array}$ & $\begin{array}{l}\text { Brazil, } \\
\text { Argentina, } \\
\text { Uruguay }\end{array}$ & $\begin{array}{l}\text { Coastal } \\
\text { grassland } \\
\text { plains }\end{array}$ & $\begin{array}{l}8-10 \\
14^{\circ} \mathrm{F}\end{array}$ & $15^{\prime}$ & Slow & Solitary & $\begin{array}{l}\text { Full } \\
\text { sun to } \\
\text { partial } \\
\text { shade }\end{array}$ & Moderate & Pinnate & Blue-green & $\begin{array}{l}\text { Hardiest of the } \\
\text { feather-leaved } \\
\text { palms. Widely } \\
\text { cultivated. Exhibits } \\
\text { variability from } \\
\text { plant to plant. Var. } \\
\text { strictior has fronds } \\
\text { with less curve. } \\
\text { Hybridizes with } \\
\text { members of the } \\
\text { genus Syagrus. }\end{array}$ \\
\hline Butia eriospatha & $\begin{array}{l}\text { Wooly jelly } \\
\text { palm }\end{array}$ & $\begin{array}{l}\text { Southern } \\
\text { Brazil }\end{array}$ & $\begin{array}{l}\text { Hillsides } \\
\text { to } 4000^{\prime}\end{array}$ & $\begin{array}{l}8-10 \\
15^{\circ} \mathrm{F}\end{array}$ & $15-20^{\prime}$ & Slow & Solitary & $\begin{array}{l}\text { Full } \\
\text { sun to } \\
\text { partial } \\
\text { shade }\end{array}$ & Moderate & Pinnate & $\begin{array}{l}\text { Blue- } \\
\text { green to } \\
\text { blue-gray }\end{array}$ & $\begin{array}{l}\text { Leaf bases } \\
\text { covered with brown } \\
\text { hair. Faster } \\
\text { growing than } B \text {. } \\
\text { capitata. }\end{array}$ \\
\hline Butia yatay & Yatay palm & $\begin{array}{l}\text { South } \\
\text { America }\end{array}$ & $\begin{array}{l}\text { Dry } \\
\text { savannas }\end{array}$ & $\begin{array}{l}8-10 \\
15^{\circ} \mathrm{F}\end{array}$ & $35^{\prime}$ & Slow & Solitary & $\begin{array}{l}\text { Full } \\
\text { sun to } \\
\text { partial } \\
\text { shade }\end{array}$ & Moderate & Pinnate & Gray-green & $\begin{array}{l}\text { Similar to } B \text {. } \\
\text { capitata, but } \\
\text { having more widely } \\
\text { spreading leaves. }\end{array}$ \\
\hline
\end{tabular}


Table 1. Palms for northern Florida and their associated characteristics ${ }^{3}$.

\begin{tabular}{|c|c|c|c|c|c|c|c|c|c|c|c|c|}
\hline $\begin{array}{l}\text { Scientific } \\
\text { Name } \\
\end{array}$ & $\begin{array}{l}\text { Common } \\
\text { Name }\end{array}$ & Origin & $\begin{array}{l}\text { Native } \\
\text { Habitat } \\
\end{array}$ & $\begin{array}{l}\text { Hardines } \\
\text { s Zone }\end{array}$ & $\begin{array}{l}\text { Typical } \\
\text { Height } \\
\end{array}$ & $\begin{array}{l}\text { Growth } \\
\text { Rate } \\
\end{array}$ & Habit & Light & $\begin{array}{l}\text { Salt } \\
\text { Tolerance } \\
\end{array}$ & $\begin{array}{l}\text { Leaf } \\
\text { Type } \\
\end{array}$ & $\begin{array}{l}\text { Foliage } \\
\text { Color } \\
\end{array}$ & Comments \\
\hline $\begin{array}{l}\text { Butia X Jubaea } \\
\text { hybrid }\end{array}$ & $\begin{array}{l}\text { No } \\
\text { common } \\
\text { name }\end{array}$ & $\begin{array}{l}\text { Occurs only } \\
\text { in cultivation }\end{array}$ & $\begin{array}{l}\text { Not } \\
\text { applicable }\end{array}$ & $\begin{array}{l}8 \mathrm{a}-10 \\
13^{\circ} \mathrm{F}\end{array}$ & $40^{\prime}+$ & Moderate & Solitary & Full sun & Moderate & Pinnate & $\begin{array}{l}\text { Bluish- } \\
\text { green }\end{array}$ & $\begin{array}{l}\text { Faster growing and } \\
\text { more cold hardy } \\
\text { than either parent. } \\
\text { Massive trunk with } \\
\text { retained leaf bases. }\end{array}$ \\
\hline $\begin{array}{l}\text { Butia X Syagrus } \\
\text { hybrid } \\
\text { X Butiagrus } \\
\text { nabonnandii }\end{array}$ & Mule palm & $\begin{array}{l}\text { Occasionally } \\
\text { produced in } \\
\text { the wild in } \\
\text { South } \\
\text { America }\end{array}$ & $\begin{array}{l}\text { Dry } \\
\text { savannas }\end{array}$ & $\begin{array}{l}8 b-10 \\
19^{\circ} \mathrm{F}\end{array}$ & $40^{\prime}+$ & Moderate & Solitary & Full sun & $\begin{array}{l}\text { Unknown } \\
\text { - likely } \\
\text { moderate }\end{array}$ & Pinnate & $\begin{array}{l}\text { Bluish- } \\
\text { green }\end{array}$ & $\begin{array}{l}\text { Resembles Butia } \\
\text { more than Syagrus } \\
\text { - but with finer, } \\
\text { less stiff foliage. } \\
\text { Faster growing } \\
\text { than Butia. }\end{array}$ \\
\hline $\begin{array}{l}\text { Chamaedorea } \\
\text { elegans }\end{array}$ & Parlor palm & $\begin{array}{l}\text { Mexico and } \\
\text { Central } \\
\text { America }\end{array}$ & $\begin{array}{l}\text { Rainforest } \\
\text { understory }\end{array}$ & $\begin{array}{l}9 a-11 \\
24^{\circ} \mathrm{F}\end{array}$ & $3-5^{\prime}$ & Slow & Solitary & $\begin{array}{l}\text { Shade } \\
\text { to } \\
\text { partial } \\
\text { shade }\end{array}$ & Low & Pinnate & Green & $\begin{array}{l}\text { Popular houseplant } \\
\text { since Victorian } \\
\text { times. Separate } \\
\text { male and female } \\
\text { plants. Most } \\
\text { effective when } \\
\text { several planted } \\
\text { together. }\end{array}$ \\
\hline $\begin{array}{l}\text { Chamaedorea } \\
\text { microspadix }\end{array}$ & $\begin{array}{l}\text { Hardy } \\
\text { bamboo } \\
\text { palm }\end{array}$ & Mexico & $\begin{array}{l}\text { Open } \\
\text { forests }\end{array}$ & $\begin{array}{l}8 b-11 \\
18^{\circ} \mathrm{F}\end{array}$ & $8^{\prime}$ & Moderate & Clustering & $\begin{array}{l}\text { Shade } \\
\text { to } \\
\text { partial } \\
\text { shade }\end{array}$ & Low & Pinnate & Dull green & $\begin{array}{l}\text { Resembles } C \text {. } \\
\text { seifrizii and } C \text {. } \\
\text { erumpens, popular } \\
\text { interior palms. }\end{array}$ \\
\hline $\begin{array}{l}\text { Chamaedorea } \\
\text { radicalis }\end{array}$ & $\begin{array}{l}\text { Radicalis } \\
\text { palm }\end{array}$ & Mexico & $\begin{array}{l}\text { High } \\
\text { elevation } \\
\text { rainforests }\end{array}$ & $\begin{array}{l}8 b-11 \\
19^{\circ} \mathrm{F}\end{array}$ & $5^{\prime}$ & $\begin{array}{l}\text { Slow to } \\
\text { moderate }\end{array}$ & Solitary & $\begin{array}{l}\text { Shade } \\
\text { to } \\
\text { partial } \\
\text { shade }\end{array}$ & Low & Pinnate & Dark green & $\begin{array}{l}\text { Often trunkless, } \\
\text { but trunked forms } \\
\text { exist. Separate } \\
\text { male and female } \\
\text { plants. }\end{array}$ \\
\hline
\end{tabular}


Table 1. Palms for northern Florida and their associated characteristics ${ }^{3}$.

\begin{tabular}{|c|c|c|c|c|c|c|c|c|c|c|c|c|}
\hline $\begin{array}{l}\text { Scientific } \\
\text { Name }\end{array}$ & $\begin{array}{l}\text { Common } \\
\text { Name }\end{array}$ & Origin & $\begin{array}{l}\text { Native } \\
\text { Habitat }\end{array}$ & $\begin{array}{l}\text { Hardines } \\
\text { s Zone }\end{array}$ & $\begin{array}{l}\text { Typical } \\
\text { Height }\end{array}$ & $\begin{array}{l}\text { Growth } \\
\text { Rate }\end{array}$ & Habit & Light & $\begin{array}{l}\text { Salt } \\
\text { Tolerance } \\
\end{array}$ & $\begin{array}{l}\text { Leaf } \\
\text { Type }\end{array}$ & $\begin{array}{l}\text { Foliage } \\
\text { Color }\end{array}$ & Comments \\
\hline $\begin{array}{l}\text { Chamaerops } \\
\text { humilis }\end{array}$ & $\begin{array}{l}\text { European } \\
\text { fan palm }\end{array}$ & $\begin{array}{l}\text { Mediterran- } \\
\text { ean Region }\end{array}$ & $\begin{array}{l}\text { Arid } \\
\text { coastal } \\
\text { zones to } \\
3000 \text { ' in } \\
\text { elevation }\end{array}$ & $\begin{array}{l}8-9 \\
16^{\circ} \mathrm{F}\end{array}$ & $10^{\prime}$ & Slow & Clustering & $\begin{array}{l}\text { Full } \\
\text { sun to } \\
\text { partial } \\
\text { shade }\end{array}$ & $\begin{array}{l}\text { Moderate } \\
\text { - may be } \\
\text { variable }\end{array}$ & Palmate & $\begin{array}{l}\text { Green, } \\
\text { blue-green } \\
\text { and silvery } \\
\text { forms }\end{array}$ & $\begin{array}{l}\text { Great variability } \\
\text { from one plant to } \\
\text { another. Var. } \\
\text { cerifera is } \\
\text { blue-green in color } \\
\text { and is not as cold } \\
\text { hardy as the green } \\
\text { form. }\end{array}$ \\
\hline $\begin{array}{l}\text { Corypha } \\
\text { umbraculifera }\end{array}$ & Talipot palm & $\begin{array}{l}\text { Southern } \\
\text { India and } \\
\text { Sri Lanka }\end{array}$ & Rainforest & $\begin{array}{l}9 a-11 \\
20^{\circ} \mathrm{F}\end{array}$ & $80^{\prime}$ & $\begin{array}{l}\text { Slow } \\
\text { when } \\
\text { young }\end{array}$ & Solitary & $\begin{array}{l}\text { Full } \\
\text { sun to } \\
\text { partial } \\
\text { shade }\end{array}$ & Low & $\begin{array}{l}\text { Costa- } \\
\text { palmate }\end{array}$ & Dull green & $\begin{array}{l}\text { Flowers after } 60- \\
80 \text { years and then } \\
\text { dies. Massive } \\
\text { leaves } 12-18 \text { in } \\
\text { diameter when } \\
\text { mature. Dies after } \\
\text { flowering }\end{array}$ \\
\hline Dypsis decipiens & $\begin{array}{l}\text { Manambe } \\
\text { palm }\end{array}$ & Madagascar & $\begin{array}{l}\text { Dry } \\
\text { highlands } \\
\text { to } 6700 \\
\text { feet }\end{array}$ & $\begin{array}{l}9 \mathrm{a}-11 \\
21^{\circ} \mathrm{F}\end{array}$ & $15^{\prime}$ & Slow & Solitary & Full sun & Low & Pinnate & Blue-green & $\begin{array}{l}\text { One of the few } \\
\text { cold-tolerant palms } \\
\text { with a crown shaft. }\end{array}$ \\
\hline Guihaia argyrata & $\begin{array}{l}\text { Dainty lady } \\
\text { palm }\end{array}$ & Vietnam & $\begin{array}{l}\text { Open } \\
\text { forests on } \\
\text { limestone } \\
\text { hills }\end{array}$ & $\begin{array}{l}9 a-11 \\
22^{\circ} \mathrm{F}\end{array}$ & $4^{\prime}$ & Slow & Clustering & $\begin{array}{l}\text { Shade } \\
\text { to } \\
\text { partial } \\
\text { shade }\end{array}$ & Low & Palmate & $\begin{array}{l}\text { Green } \\
\text { above, } \\
\text { silvery } \\
\text { white } \\
\text { below }\end{array}$ & $\begin{array}{l}\text { First placed in the } \\
\text { genus } \\
\text { Trachycarpus. } \\
\text { Grows best at } \\
\text { higher pH. }\end{array}$ \\
\hline $\begin{array}{l}\text { Howea } \\
\text { forsteriana }\end{array}$ & Kentia palm & $\begin{array}{l}\text { Lord Howe } \\
\text { Island, New } \\
\text { South } \\
\text { Wales, } \\
\text { Australia }\end{array}$ & & $\begin{array}{l}9 \mathrm{a}-11 \\
24^{\circ} \mathrm{F}\end{array}$ & $6-14^{\prime}$ & Slow & Solitary & $\begin{array}{l}\text { Partial } \\
\text { shade }\end{array}$ & Moderate & Pinnate & $\begin{array}{l}\text { Dark } \\
\text { green } \\
\text { above, } \\
\text { lighter } \\
\text { below }\end{array}$ & $\begin{array}{l}\text { Excellent container } \\
\text { plant. }\end{array}$ \\
\hline
\end{tabular}


Table 1. Palms for northern Florida and their associated characteristics ${ }^{3}$.

\begin{tabular}{|c|c|c|c|c|c|c|c|c|c|c|c|c|}
\hline $\begin{array}{l}\text { Scientific } \\
\text { Name }\end{array}$ & $\begin{array}{l}\text { Common } \\
\text { Name }\end{array}$ & Origin & $\begin{array}{l}\text { Native } \\
\text { Habitat }\end{array}$ & $\begin{array}{l}\text { Hardines } \\
\text { s Zone }\end{array}$ & $\begin{array}{l}\text { Typical } \\
\text { Height }\end{array}$ & $\begin{array}{l}\text { Growth } \\
\text { Rate }\end{array}$ & Habit & Light & $\begin{array}{l}\text { Salt } \\
\text { Tolerance }\end{array}$ & $\begin{array}{l}\text { Leaf } \\
\text { Type }\end{array}$ & $\begin{array}{l}\text { Foliage } \\
\text { Color }\end{array}$ & Comments \\
\hline Jubaea chilensis & $\begin{array}{l}\text { Chilean } \\
\text { wine palm }\end{array}$ & Chile & $\begin{array}{l}\text { Desert, } \\
\text { coastal } \\
\text { valleys }\end{array}$ & $\begin{array}{l}8 b-10 a \\
14^{\circ} \mathrm{F}\end{array}$ & $50-80^{\prime}$ & Very slow & Solitary & Full sun & Low & Pinnate & $\begin{array}{l}\text { Dull green } \\
\text { above, } \\
\text { gray below }\end{array}$ & $\begin{array}{l}\text { Requires well } \\
\text { drained soil. Has } \\
\text { the thickest trunk } \\
\text { of any palm - up } \\
\text { to } 6 \text { feet in } \\
\text { diameter. }\end{array}$ \\
\hline $\begin{array}{l}\text { Latania } \\
\text { lontaroides }\end{array}$ & $\begin{array}{l}\text { Red latan } \\
\text { palm }\end{array}$ & $\begin{array}{l}\text { Reunion } \\
\text { Island } \\
\text { (Mascarenes) }\end{array}$ & $\begin{array}{l}\text { Cliffs and } \\
\text { coastal } \\
\text { ravines }\end{array}$ & $\begin{array}{l}9 a-11 \\
24^{\circ} \mathrm{F}\end{array}$ & $30^{\prime}$ & Slow & Solitary & Full sun & Moderate & $\begin{array}{l}\text { Costa- } \\
\text { palmate }\end{array}$ & $\begin{array}{l}\text { Gray- } \\
\text { green and } \\
\text { slightly } \\
\text { waxy }\end{array}$ & $\begin{array}{l}\text { Distinctive red } \\
\text { coloration when } \\
\text { young. Drought } \\
\text { tolerant. }\end{array}$ \\
\hline $\begin{array}{l}\text { Livistona } \\
\text { australis }\end{array}$ & $\begin{array}{l}\text { Australian } \\
\text { fan palm }\end{array}$ & Australia & $\begin{array}{l}\text { Rainforest } \\
\text { understory }\end{array}$ & $\begin{array}{l}9 a-11 \\
22^{\circ} \mathrm{F}\end{array}$ & $40^{\prime}$ & Slow & Solitary & $\begin{array}{l}\text { Partial } \\
\text { shade } \\
\text { to full } \\
\text { sun }\end{array}$ & Moderate & Palmate & $\begin{array}{l}\text { Deep, } \\
\text { glossy } \\
\text { green }\end{array}$ & $\begin{array}{l}\text { Secondmost cold } \\
\text { hardy Livistona } \\
\text { after L. chinensis. }\end{array}$ \\
\hline $\begin{array}{l}\text { Livistona } \\
\text { chinensis }\end{array}$ & $\begin{array}{l}\text { Chinese } \\
\text { fan palm }\end{array}$ & $\begin{array}{l}\text { China, } \\
\text { southern } \\
\text { Japan }\end{array}$ & $\begin{array}{l}\text { Open } \\
\text { forests }\end{array}$ & $\begin{array}{l}8 b-11 \\
18^{\circ} \mathrm{F}\end{array}$ & $25^{\prime}$ & Slow & Solitary & $\begin{array}{l}\text { Partial } \\
\text { shade } \\
\text { to full } \\
\text { sun }\end{array}$ & Moderate & Palmate & $\begin{array}{l}\text { Olive } \\
\text { Green }\end{array}$ & $\begin{array}{l}\text { Often defoliated by } \\
\text { hard freezes, but } \\
\text { re-grows a new } \\
\text { canopy in spring. } \\
\text { Rarely forms trunk } \\
\text { in northern regions. } \\
\text { Armed petiole }\end{array}$ \\
\hline $\begin{array}{l}\text { Livistona } \\
\text { decipiens }\end{array}$ & $\begin{array}{l}\text { Ribbon fan } \\
\text { palm }\end{array}$ & Australia & $\begin{array}{l}\text { River } \\
\text { banks and } \\
\text { coastal } \\
\text { areas }\end{array}$ & $\begin{array}{l}9 a-11 \\
23^{\circ} \mathrm{F}\end{array}$ & $30^{\prime}$ & $\begin{array}{l}\text { Slow to } \\
\text { moderate }\end{array}$ & Solitary & $\begin{array}{l}\text { Partial } \\
\text { shade } \\
\text { to full } \\
\text { sun }\end{array}$ & Moderate & Palmate & $\begin{array}{l}\text { Deep } \\
\text { green } \\
\text { above, } \\
\text { waxy gray } \\
\text { below }\end{array}$ & $\begin{array}{l}\text { The leaves are } \\
\text { deeply divided and } \\
\text { the long segments } \\
\text { hang downward in } \\
\text { a curtain-like } \\
\text { manner. }\end{array}$ \\
\hline
\end{tabular}


Table 1. Palms for northern Florida and their associated characteristics ${ }^{3}$

\begin{tabular}{|c|c|c|c|c|c|c|c|c|c|c|c|c|}
\hline $\begin{array}{l}\text { Scientific } \\
\text { Name }\end{array}$ & $\begin{array}{l}\text { Common } \\
\text { Name }\end{array}$ & Origin & $\begin{array}{l}\text { Native } \\
\text { Habitat }\end{array}$ & $\begin{array}{l}\text { Hardines } \\
\text { s Zone }\end{array}$ & $\begin{array}{l}\text { Typical } \\
\text { Height }\end{array}$ & $\begin{array}{l}\text { Growth } \\
\text { Rate }\end{array}$ & Habit & Light & $\begin{array}{l}\text { Salt } \\
\text { Tolerance } \\
\end{array}$ & $\begin{array}{l}\text { Leaf } \\
\text { Type }\end{array}$ & $\begin{array}{l}\text { Foliage } \\
\text { Color }\end{array}$ & Comments \\
\hline $\begin{array}{l}\text { Nannorrhops } \\
\text { ritchiana }\end{array}$ & Mazari palm & $\begin{array}{l}\text { Afghanistan, } \\
\text { Pakistan to } \\
\text { Arabia }\end{array}$ & $\begin{array}{l}\text { Desert } \\
\text { mountain } \\
\text { regions }\end{array}$ & $\begin{array}{l}7 \mathrm{~b}-11 \\
7^{\circ} \mathrm{F}\end{array}$ & $10^{\prime}$ & Slow & Clustering & Full sun & Moderate & $\begin{array}{l}\text { Costa- } \\
\text { palmate }\end{array}$ & Blue-green & $\begin{array}{l}\text { Requires } \\
\text { well-drained soil. } \\
\text { After flowering and } \\
\text { fruiting, a stem will } \\
\text { eventually die } \\
\text { back, but not } \\
\text { before branching } \\
\text { just below the } \\
\text { crown. }\end{array}$ \\
\hline $\begin{array}{l}\text { Phoenix } \\
\text { canariensis }\end{array}$ & $\begin{array}{l}\text { Canary } \\
\text { Island date } \\
\text { palm }\end{array}$ & $\begin{array}{l}\text { Canary } \\
\text { Islands }\end{array}$ & $\begin{array}{l}\text { Desert } \\
\text { regions, } \\
600- \\
1900^{\prime}\end{array}$ & $\begin{array}{l}8 b-11 \\
19^{\circ} \mathrm{F}\end{array}$ & $40^{\prime}$ & Very slow & Solitary & Full sun & Moderate & Pinnate & $\begin{array}{l}\text { Dull deep } \\
\text { green }\end{array}$ & $\begin{array}{l}\text { Form impressive, } \\
\text { large specimens. } \\
\text { Poorly drained } \\
\text { sites should be } \\
\text { avoided. }\end{array}$ \\
\hline $\begin{array}{l}\text { Phoenix } \\
\text { dactylifera }\end{array}$ & Date palm & $\begin{array}{l}\text { North Africa } \\
\text { - exact } \\
\text { origin } \\
\text { unknown }\end{array}$ & $\begin{array}{l}\text { Desert } \\
\text { regions }\end{array}$ & $\begin{array}{l}8 b-11 \\
19^{\circ} \mathrm{F}\end{array}$ & $40-50^{\prime}$ & Slow & $\begin{array}{l}\text { Slowly } \\
\text { clustering }\end{array}$ & Full sun & High & Pinnate & Gray-green & $\begin{array}{l}\text { Most landscape } \\
\text { specimens } \\
\text { transplanted from } \\
\text { date groves in AZ } \\
\text { or CA. }\end{array}$ \\
\hline $\begin{array}{l}\text { Phoenix } \\
\text { reclinata }^{5}\end{array}$ & $\begin{array}{l}\text { Senegal } \\
\text { date palm }\end{array}$ & Africa & $\begin{array}{l}\text { Desert } \\
\text { regions }\end{array}$ & $\begin{array}{l}9 a-11 \\
25^{\circ} \mathrm{F}\end{array}$ & $24-30^{\prime}$ & Moderate & Clustering & Full sun & Moderate & Pinnate & Dark green & $\begin{array}{l}\text { Suckers } \\
\text { vigorously. } \\
\text { Slender trunks. } \\
\text { Thicker trunks may } \\
\text { indicate } \\
\text { hybridization with } \\
\text { other Phoenix } \\
\text { species, and may } \\
\text { be indicative of } \\
\text { greater cold } \\
\text { tolerance. }\end{array}$ \\
\hline
\end{tabular}


Table 1. Palms for northern Florida and their associated characteristics ${ }^{3}$.

\begin{tabular}{|c|c|c|c|c|c|c|c|c|c|c|c|c|}
\hline $\begin{array}{l}\text { Scientific } \\
\text { Name }\end{array}$ & $\begin{array}{l}\text { Common } \\
\text { Name }\end{array}$ & Origin & $\begin{array}{l}\text { Native } \\
\text { Habitat }\end{array}$ & $\begin{array}{l}\text { Hardines } \\
\text { s Zone }\end{array}$ & $\begin{array}{l}\text { Typical } \\
\text { Height }\end{array}$ & $\begin{array}{l}\text { Growth } \\
\text { Rate }\end{array}$ & Habit & Light & $\begin{array}{l}\text { Salt } \\
\text { Tolerance }\end{array}$ & $\begin{array}{l}\text { Leaf } \\
\text { Type }\end{array}$ & $\begin{array}{l}\text { Foliage } \\
\text { Color }\end{array}$ & Comments \\
\hline $\begin{array}{l}\text { Phoenix } \\
\text { roebelenii }\end{array}$ & $\begin{array}{l}\text { Pygmy } \\
\text { date palm }\end{array}$ & $\begin{array}{l}\text { Southeast } \\
\text { Asia - } \\
\text { Laos, } \\
\text { Vietnam, } \\
\text { Thailand }\end{array}$ & Rainforests & $\begin{array}{l}9 a-11 \\
24^{\circ} \mathrm{F}\end{array}$ & $10^{\prime}$ & Slow & Solitary & $\begin{array}{l}\text { Partial } \\
\text { shade } \\
\text { to full } \\
\text { sun }\end{array}$ & Low & Pinnate & $\begin{array}{l}\text { Glossy } \\
\text { green }\end{array}$ & $\begin{array}{l}\text { May require some } \\
\text { protection in } \\
\text { particularly cold } \\
\text { periods. Separate } \\
\text { male and female } \\
\text { plants. Adapts well } \\
\text { to container } \\
\text { production. }\end{array}$ \\
\hline $\begin{array}{l}\text { Phoenix } \\
\text { sylvestris }\end{array}$ & $\begin{array}{l}\text { Wild date } \\
\text { palm }\end{array}$ & India & $\begin{array}{l}\text { Desert } \\
\text { regions }\end{array}$ & $\begin{array}{l}9 a-11 \\
22^{\circ} \mathrm{F}\end{array}$ & $40^{\prime}$ & Slow & Solitary & Full sun & Moderate & Pinnate & Blue-green & $\begin{array}{l}\text { Shorter leaves } \\
\text { than } P \text {. canariensis } \\
\text { and } P \text {. dactylifera. } \\
\text { Hybridizes with } \\
\text { other Phoenix } \\
\text { species. }\end{array}$ \\
\hline $\begin{array}{l}\text { Phoenix } \\
\text { theophrastii }\end{array}$ & $\begin{array}{l}\text { Cretan } \\
\text { date palm }\end{array}$ & $\begin{array}{l}\text { Crete, } \\
\text { limited } \\
\text { areas of } \\
\text { Turkey }\end{array}$ & $\begin{array}{l}\text { Arid, } \\
\text { desert-like } \\
\text { regions }\end{array}$ & $\begin{array}{l}8 b-11 \\
19^{\circ} \mathrm{F}\end{array}$ & $25^{\prime}$ & Slow & Clustering & Full sun & Moderate & Pinnate & $\begin{array}{l}\text { Silvery- } \\
\text { gray }\end{array}$ & $\begin{array}{l}\text { Similar to } P \text {. } \\
\text { reclinata, but more } \\
\text { cold hardy. }\end{array}$ \\
\hline $\begin{array}{l}\text { Rhapidophyllum } \\
\text { hystrix }\end{array}$ & $\begin{array}{l}\text { Needle } \\
\text { palm }\end{array}$ & $\begin{array}{l}\text { Southeastern } \\
\text { US }\end{array}$ & $\begin{array}{l}\text { Dry, pine } \\
\text { flatwoods }\end{array}$ & $\begin{array}{l}7 b-10 a \\
5^{\circ} \mathrm{F}\end{array}$ & $5^{\prime}$ & Slow & Clustering & $\begin{array}{l}\text { Partial } \\
\text { shade } \\
\text { to full } \\
\text { sun }\end{array}$ & Moderate & Palmate & $\begin{array}{l}\text { Dark } \\
\text { green } \\
\text { above, } \\
\text { silvery } \\
\text { below }\end{array}$ & $\begin{array}{l}\text { Florida native. } \\
\text { Separate male and } \\
\text { female plants. } 10 \\
-12 " \text { needles from } \\
\text { crown. }\end{array}$ \\
\hline Rhapis excelsa & Lady palm & China & $\begin{array}{l}\text { Forest } \\
\text { understory }\end{array}$ & $\begin{array}{l}9 a-11 \\
21^{\circ} \mathrm{F}\end{array}$ & $7^{\prime}$ & Moderate & Clustering & $\begin{array}{l}\text { Shade } \\
\text { to } \\
\text { partial } \\
\text { shade }\end{array}$ & Moderate & Palmate & $\begin{array}{l}\text { Shiny } \\
\text { Green }\end{array}$ & $\begin{array}{l}\text { Leaves tend to } \\
\text { yellow with too } \\
\text { much sun. } \\
\text { Excellent container } \\
\text { plant. Variegated } \\
\text { forms available, } \\
\text { but very expensive. }\end{array}$ \\
\hline Rhapis humilis & $\begin{array}{l}\text { Slender } \\
\text { lady palm }\end{array}$ & China & $\begin{array}{l}\text { Known } \\
\text { only in } \\
\text { culture }\end{array}$ & $\begin{array}{l}9 a-11 \\
21^{\circ} \mathrm{F}\end{array}$ & $13^{\prime}$ & Slow & Clustering & $\begin{array}{l}\text { Shade } \\
\text { to } \\
\text { partial } \\
\text { shade }\end{array}$ & Moderate & Palmate & $\begin{array}{l}\text { Green, } \\
\text { slightly } \\
\text { shiny }\end{array}$ & $\begin{array}{l}\text { Smaller stems and } \\
\text { leaves than } R \text {. } \\
\text { excelsa. All plants } \\
\text { are male; no } \\
\text { females exist. }\end{array}$ \\
\hline
\end{tabular}


Table 1. Palms for northern Florida and their associated characteristics ${ }^{3}$.

\begin{tabular}{|c|c|c|c|c|c|c|c|c|c|c|c|c|}
\hline $\begin{array}{l}\text { Scientific } \\
\text { Name } \\
\end{array}$ & $\begin{array}{l}\text { Common } \\
\text { Name }\end{array}$ & Origin & $\begin{array}{l}\text { Native } \\
\text { Habitat }\end{array}$ & $\begin{array}{l}\text { Hardines } \\
\text { s Zone }\end{array}$ & $\begin{array}{l}\text { Typical } \\
\text { Height }\end{array}$ & $\begin{array}{l}\text { Growth } \\
\text { Rate } \\
\end{array}$ & Habit & Light & $\begin{array}{l}\text { Salt } \\
\text { Tolerance } \\
\end{array}$ & $\begin{array}{l}\text { Leaf } \\
\text { Type } \\
\end{array}$ & $\begin{array}{l}\text { Foliage } \\
\text { Color }\end{array}$ & Comments \\
\hline $\begin{array}{l}\text { Sabal } \\
\text { bermudana }\end{array}$ & $\begin{array}{l}\text { Bermuda } \\
\text { palmetto }\end{array}$ & Bermuda & $\begin{array}{l}\text { Sandy, } \\
\text { dry regions }\end{array}$ & $\begin{array}{l}8 b-11 \\
16^{\circ} \mathrm{F}\end{array}$ & $25^{\prime}$ & Slow & Solitary & Full sun & $\begin{array}{l}\text { Moderate } \\
\text { to high }\end{array}$ & $\begin{array}{l}\text { Costa- } \\
\text { palmate }\end{array}$ & Blue-green & $\begin{array}{l}\text { Requires } \\
\text { well-drained } \\
\text { location. }\end{array}$ \\
\hline Sabal causiarum & $\begin{array}{l}\text { Puerto } \\
\text { Rican hat } \\
\text { palm }\end{array}$ & Puerto Rico & $\begin{array}{l}\text { Sandy, } \\
\text { dry regions }\end{array}$ & $\begin{array}{l}8 b-11 \\
19^{\circ} \mathrm{F} \\
\end{array}$ & $50^{\prime}$ & Slow & Solitary & Full sun & $\begin{array}{l}\text { Moderate } \\
\text { to high }\end{array}$ & $\begin{array}{l}\text { Costa- } \\
\text { palmate }\end{array}$ & Green & $\begin{array}{l}\text { Massive trunk, not } \\
\text { frequently seen in } \\
\text { the landscape. }\end{array}$ \\
\hline $\begin{array}{l}\text { Sabal } \\
\text { domingensis }\end{array}$ & $\begin{array}{l}\text { Dominican } \\
\text { palmetto }\end{array}$ & $\begin{array}{l}\text { Haiti, } \\
\text { Hispanola, } \\
\text { eastern } \\
\text { Cuba } \\
\end{array}$ & $\begin{array}{l}\text { Hot dry } \\
\text { inland } \\
\text { areas to } \\
3300^{\prime} \\
\end{array}$ & $\begin{array}{l}9 a-11 \\
22^{\circ} \mathrm{F}\end{array}$ & $60^{\prime}$ & $\begin{array}{l}\text { Slow to } \\
\text { moderate }\end{array}$ & Solitary & Full sun & $\begin{array}{l}\text { Moderate } \\
\text { to high }\end{array}$ & $\begin{array}{l}\text { Costa- } \\
\text { palmate }\end{array}$ & Green & $\begin{array}{l}\text { Large whitish } \\
\text { trunk. Thrives on } \\
\text { sandy soils }\end{array}$ \\
\hline Sabal etonia & $\begin{array}{l}\text { Scrub } \\
\text { palmetto }\end{array}$ & $\begin{array}{l}\text { Southeastern } \\
\text { US }\end{array}$ & $\begin{array}{l}\text { Dry } \\
\text { scrublands }\end{array}$ & $\begin{array}{l}8 b-10 \\
16^{\circ} \mathrm{F}\end{array}$ & $5^{\prime}$ & Slow & Solitary & $\begin{array}{l}\text { Partial } \\
\text { shade } \\
\text { to full } \\
\text { sun }\end{array}$ & Moderate & $\begin{array}{l}\text { Costa- } \\
\text { palmate } \\
\text { to } \\
\text { palmate } \\
\end{array}$ & $\begin{array}{l}\text { Dull green } \\
\text { to } \\
\text { blue-green }\end{array}$ & $\begin{array}{l}\text { Similar to S. minor } \\
\text { but has smaller, } \\
\text { deeply folded } \\
\text { leaves. }\end{array}$ \\
\hline Sabal mexicana & $\begin{array}{l}\text { Rio Grande } \\
\text { palmetto }\end{array}$ & $\begin{array}{l}\text { Texas, } \\
\text { Mexico, El } \\
\text { Salvador }\end{array}$ & $\begin{array}{l}\text { Arid, } \\
\text { desert-like } \\
\text { regions }\end{array}$ & $\begin{array}{l}8 b-11 \\
17^{\circ} \mathrm{F}\end{array}$ & $40^{\prime}$ & Slow & Solitary & Full sun & Moderate & $\begin{array}{l}\text { Costa- } \\
\text { palmate }\end{array}$ & $\begin{array}{l}\text { Emerald } \\
\text { green }\end{array}$ & $\begin{array}{l}\text { Drought tolerant, } \\
\text { but grows faster } \\
\text { with adequate } \\
\text { water. }\end{array}$ \\
\hline Sabal minor & $\begin{array}{l}\text { Dwarf } \\
\text { palmetto }\end{array}$ & $\begin{array}{l}\text { Southeastern } \\
\text { US }\end{array}$ & $\begin{array}{l}\text { Understory } \\
\text { of pine } \\
\text { flatwoods }\end{array}$ & $\begin{array}{l}7 a-10 b \\
5^{\circ} \mathrm{F}\end{array}$ & $6^{\prime}$ & Slow & Solitary & $\begin{array}{l}\text { Partial } \\
\text { shade } \\
\text { to } \\
\text { shade }\end{array}$ & Moderate & $\begin{array}{l}\text { Costa- } \\
\text { palmate } \\
\text { to } \\
\text { palmate }\end{array}$ & $\begin{array}{l}\text { Green to } \\
\text { blue-green }\end{array}$ & $\begin{array}{l}\text { Does not form a } \\
\text { trunk. Larger } \\
\text { crown than } S \text {. } \\
\text { palmetto. }\end{array}$ \\
\hline Sabal palmetto & $\begin{array}{l}\text { Cabbage } \\
\text { palm }\end{array}$ & $\begin{array}{l}\text { Southeastern } \\
\text { US }\end{array}$ & & $\begin{array}{l}8 a-11 \\
10^{\circ} \mathrm{F}\end{array}$ & $30-40^{\prime}$ & Slow & Solitary & Full sun & High & $\begin{array}{l}\text { Costa- } \\
\text { palmate }\end{array}$ & Dull green & $\begin{array}{l}\text { The state tree of } \\
\text { both } \mathrm{FL} \text { and } \mathrm{SC} \text {. } \\
\text { Adapts well to } \\
\text { many different soils } \\
\text { and situations. }\end{array}$ \\
\hline Sabal rosei & Llana Palm & $\begin{array}{l}\text { Western } \\
\text { Mexico }\end{array}$ & $\begin{array}{l}\text { Dry } \\
\text { savannas }\end{array}$ & $\begin{array}{l}8 a-11 \\
10^{\circ} \mathrm{F}\end{array}$ & $25-30^{\prime}$ & Slow & Solitary & Full sun & & $\begin{array}{l}\text { Costa- } \\
\text { palmate }\end{array}$ & Blue-green & $\begin{array}{l}\text { Drought and flood } \\
\text { tolerant. Trunk is } \\
\text { more slender than } \\
\text { that of } S \text {. palmetto. }\end{array}$ \\
\hline $\begin{array}{l}\text { Sabal } \\
\text { umbraculifera }\end{array}$ & $\begin{array}{l}\text { Hispanolian } \\
\text { palm }\end{array}$ & $\begin{array}{l}\text { Santo } \\
\text { Domingo }\end{array}$ & & $\begin{array}{l}7 b-11 \\
9^{\circ} \mathrm{F}\end{array}$ & $60^{\prime}$ & Slow & Solitary & Full sun & High & $\begin{array}{l}\text { Costa- } \\
\text { palmate }\end{array}$ & Dull green & $\begin{array}{l}\text { Stout, heavy trunk } \\
\text { with very large } \\
\text { leaves. Thrives on } \\
\text { sandy soil. }\end{array}$ \\
\hline
\end{tabular}


Table 1. Palms for northern Florida and their associated characteristics ${ }^{3}$.

\begin{tabular}{|c|c|c|c|c|c|c|c|c|c|c|c|c|}
\hline $\begin{array}{l}\text { Scientific } \\
\text { Name }\end{array}$ & $\begin{array}{l}\text { Common } \\
\text { Name }\end{array}$ & Origin & $\begin{array}{l}\text { Native } \\
\text { Habitat }\end{array}$ & $\begin{array}{l}\text { Hardines } \\
\text { s Zone }\end{array}$ & $\begin{array}{l}\text { Typical } \\
\text { Height }\end{array}$ & $\begin{array}{l}\text { Growth } \\
\text { Rate }\end{array}$ & Habit & Light & $\begin{array}{l}\text { Salt } \\
\text { Tolerance }\end{array}$ & $\begin{array}{l}\text { Leaf } \\
\text { Type }\end{array}$ & $\begin{array}{l}\text { Foliage } \\
\text { Color }\end{array}$ & Comments \\
\hline Sabal uresana & $\begin{array}{l}\text { Soronan } \\
\text { palmetto }\end{array}$ & Mexico & $\begin{array}{l}\text { Open } \\
\text { forest }\end{array}$ & $\begin{array}{l}8 b-11 \\
14^{\circ} \mathrm{F}\end{array}$ & $60^{\prime}+$ & Slow & Solitary & Full sun & Moderate & $\begin{array}{l}\text { Costa- } \\
\text { palmate }\end{array}$ & $\begin{array}{l}\text { Silvery- } \\
\text { blue }\end{array}$ & $\begin{array}{l}\text { Bluish tint to } \\
\text { foliage becomes } \\
\text { less distinct as the } \\
\text { plant ages. }\end{array}$ \\
\hline Serenoa repens & $\begin{array}{l}\text { Saw } \\
\text { palmetto }\end{array}$ & $\begin{array}{l}\text { Southeaster } \\
\text { n US }\end{array}$ & $\begin{array}{l}\text { Dry pine } \\
\text { flatwoods }\end{array}$ & $\begin{array}{l}8 b-11 \\
18^{\circ} \mathrm{F}\end{array}$ & $3-6^{\prime}$ & Slow & Clumping & $\begin{array}{l}\text { Partial } \\
\text { shade } \\
\text { to full } \\
\text { sun }\end{array}$ & High & Palmate & $\begin{array}{l}\text { Green or } \\
\text { blue } \\
\text { green, } \\
\text { waxy }\end{array}$ & $\begin{array}{l}\text { Florida native. } \\
\text { Large specimens } \\
\text { do not transplant } \\
\text { easily. }\end{array}$ \\
\hline $\begin{array}{l}\text { Syagrus } \\
\text { romanzoffiana }^{6}\end{array}$ & Queen palm & $\begin{array}{l}\text { Brazil to } \\
\text { Argentina }\end{array}$ & $\begin{array}{l}\text { Lowland } \\
\text { humid } \\
\text { forests }\end{array}$ & $\begin{array}{l}9 a-11 \\
23^{\circ} \mathrm{F}\end{array}$ & $30^{\prime}$ & Fast & Solitary & $\begin{array}{l}\text { Full } \\
\text { sun to } \\
\text { partial } \\
\text { shade }\end{array}$ & Moderate & Pinnate & Dark green & $\begin{array}{l}\text { Susceptible to Mn } \\
\text { deficiency on } \\
\text { high-pH soil. } \\
\text { Produces large } \\
\text { numbers of fruit } \\
\text { which some } \\
\text { consider messy. }\end{array}$ \\
\hline $\begin{array}{l}\text { Trachycarpus } \\
\text { fortunei }\end{array}$ & $\begin{array}{l}\text { Windmill } \\
\text { palm, } \\
\text { chusan } \\
\text { palm }\end{array}$ & China & $\begin{array}{l}\text { Mountain } \\
\text { regions to } \\
7500^{\prime}\end{array}$ & $\begin{array}{l}8 a-10 a \\
10^{\circ} \mathrm{F}\end{array}$ & $20^{\prime}$ & Slow & Solitary & $\begin{array}{l}\text { Partial } \\
\text { shade } \\
\text { to full } \\
\text { sun }\end{array}$ & Moderate & Palmate & $\begin{array}{l}\text { Dark } \\
\text { green } \\
\text { above, } \\
\text { silvery } \\
\text { below }\end{array}$ & $\begin{array}{l}\text { Fiber-covered } \\
\text { trunk. Very cold } \\
\text { hardy, even } \\
\text { tolerating light } \\
\text { snow. }\end{array}$ \\
\hline $\begin{array}{l}\text { Trachycarpus } \\
\text { latisectus }\end{array}$ & $\begin{array}{l}\text { Windamere } \\
\text { palm }\end{array}$ & $\begin{array}{l}\text { Himalayas } \\
\text { of northern } \\
\text { India }\end{array}$ & $\begin{array}{l}\text { Mountain } \\
\text { regions to } \\
8000^{\prime}\end{array}$ & $\begin{array}{l}7 \mathrm{a}-10 \mathrm{a} \\
1^{\circ} \mathrm{F}\end{array}$ & $\overline{18^{\prime}}$ & Slow & Solitary & $\begin{array}{l}\text { Partial } \\
\text { shade } \\
\text { to full } \\
\text { sun }\end{array}$ & Moderate & Palmate & $\begin{array}{l}\text { Dark } \\
\text { green }\end{array}$ & $\begin{array}{l}\text { Leaves shed } \\
\text { naturally, leaving a } \\
\text { smooth slender } \\
\text { trunk. Unknown } \\
\text { before } 1992 \text {. }\end{array}$ \\
\hline $\begin{array}{l}\text { Trachycarpus } \\
\text { martianus }\end{array}$ & $\begin{array}{l}\text { Himilayan } \\
\text { windmill } \\
\text { palm }\end{array}$ & $\begin{array}{l}\text { China, } \\
\text { Nepal, India }\end{array}$ & $\begin{array}{l}\text { Mountain } \\
\text { regions }\end{array}$ & $\begin{array}{l}9 a-10 a \\
23^{\circ} \mathrm{F}\end{array}$ & $20^{\prime}$ & Slow & Solitary & $\begin{array}{l}\text { Partial } \\
\text { shade } \\
\text { to full } \\
\text { sun }\end{array}$ & Moderate & Palmate & $\begin{array}{l}\text { Green } \\
\text { above, } \\
\text { silvery } \\
\text { below }\end{array}$ & $\begin{array}{l}\text { Slimmer trunk than } \\
\text { T. fortunei. New } \\
\text { growth covered by } \\
\text { whitish } \\
\text { pubescence. }\end{array}$ \\
\hline $\begin{array}{l}\text { Trachycarpus } \\
\text { oreophilus }\end{array}$ & $\begin{array}{l}\text { Thai } \\
\text { mountain } \\
\text { fan palm }\end{array}$ & $\begin{array}{l}\text { Northwest } \\
\text { Thailand }\end{array}$ & $\begin{array}{l}\text { Rocky } \\
\text { outcrops, } \\
\text { mountain } \\
\text { regions }\end{array}$ & $\begin{array}{l}8 a-10 a \\
14^{\circ} \mathrm{F}\end{array}$ & $30^{\prime}$ & Slow & Solitary & $\begin{array}{l}\text { Partial } \\
\text { shade } \\
\text { to full } \\
\text { sun }\end{array}$ & Unknown & Palmate & $\begin{array}{l}\text { Green } \\
\text { above, } \\
\text { silvery } \\
\text { below }\end{array}$ & $\begin{array}{l}\text { Small compact } \\
\text { crown of foliage. } \\
\text { Smooth, slender } \\
\text { trunk. }\end{array}$ \\
\hline
\end{tabular}


Table 1. Palms for northern Florida and their associated characteristics ${ }^{3}$.

\begin{tabular}{|c|c|c|c|c|c|c|c|c|c|c|c|c|}
\hline $\begin{array}{l}\text { Scientific } \\
\text { Name }\end{array}$ & $\begin{array}{l}\text { Common } \\
\text { Name }\end{array}$ & Origin & $\begin{array}{l}\text { Native } \\
\text { Habitat }\end{array}$ & $\begin{array}{l}\text { Hardines } \\
\text { s Zone }\end{array}$ & $\begin{array}{l}\text { Typical } \\
\text { Height }\end{array}$ & $\begin{array}{l}\text { Growth } \\
\text { Rate }\end{array}$ & Habit & Light & $\begin{array}{l}\text { Salt } \\
\text { Tolerance }\end{array}$ & $\begin{array}{l}\text { Leaf } \\
\text { Type }\end{array}$ & $\begin{array}{l}\text { Foliage } \\
\text { Color }\end{array}$ & Comments \\
\hline $\begin{array}{l}\text { Trachycarpus } \\
\text { takil }\end{array}$ & $\begin{array}{l}\text { Kamaon } \\
\text { fan palm }\end{array}$ & $\begin{array}{l}\text { North } \\
\text { central India }\end{array}$ & $\begin{array}{l}\text { Mountain } \\
\text { regions to } \\
8000^{\prime}\end{array}$ & $\begin{array}{l}7 b-10 a \\
6^{\circ} F\end{array}$ & $25^{\prime}$ & $\begin{array}{l}\text { Slow to } \\
\text { moderate }\end{array}$ & Solitary & $\begin{array}{l}\text { Partial } \\
\text { shade } \\
\text { to full } \\
\text { sun }\end{array}$ & Unknown & Palmate & Green & $\begin{array}{l}\text { Compact growth } \\
\text { habit. Smooth } \\
\text { trunk. }\end{array}$ \\
\hline $\begin{array}{l}\text { Trachycarpus } \\
\text { wagnerianus }\end{array}$ & $\begin{array}{l}\text { Wagner's } \\
\text { fan palm }\end{array}$ & Japan & $\begin{array}{l}\text { Unknown } \\
\text { in the wild }\end{array}$ & $\begin{array}{l}8 a-10 a \\
13^{\circ} \mathrm{F}\end{array}$ & $10^{\prime}$ & Slow & Solitary & $\begin{array}{l}\text { Partial } \\
\text { shade } \\
\text { to full } \\
\text { sun }\end{array}$ & Unknown & Palmate & $\begin{array}{l}\text { Green } \\
\text { above, } \\
\text { silver } \\
\text { below }\end{array}$ & $\begin{array}{l}\text { Similar to } T \text {. } \\
\text { fortunei, but } \\
\text { smaller. } \\
\text { Fiber-covered } \\
\text { trunk. }\end{array}$ \\
\hline $\begin{array}{l}\text { Trithrinax } \\
\text { acanthocoma }\end{array}$ & $\begin{array}{l}\text { Spiny fiber } \\
\text { palm }\end{array}$ & $\begin{array}{l}\text { Southern } \\
\text { Brazil }\end{array}$ & $\begin{array}{l}\text { Open } \\
\text { forests, } \\
\text { dry } \\
\text { savannas }\end{array}$ & $\begin{array}{l}9 a-11 \\
20^{\circ} \mathrm{F}\end{array}$ & $15^{\prime}$ & Slow & Solitary & Full sun & Moderate & Palmate & $\begin{array}{l}\text { Deep } \\
\text { green } \\
\text { above, } \\
\text { whitish } \\
\text { below } \\
\end{array}$ & $\begin{array}{l}\text { Not widely } \\
\text { cultivated. Long } \\
\text { spines on trunk. }\end{array}$ \\
\hline $\begin{array}{l}\text { Trithrinax } \\
\text { campestris }\end{array}$ & $\begin{array}{l}\text { Blue } \\
\text { needle } \\
\text { palm, } \\
\text { Caranday } \\
\text { palm }\end{array}$ & $\begin{array}{l}\text { Argentina } \\
\text { and Uruguay }\end{array}$ & $\begin{array}{l}\text { Arid } \\
\text { regions }\end{array}$ & $\begin{array}{l}8 a-11 \\
13^{\circ} \mathrm{F}\end{array}$ & $12^{\prime}$ & Slow & Clumping & Full sun & High & Palmate & Blue-green & $\begin{array}{l}\text { Erect, stiff leaflets. } \\
\text { Drought tolerant. } \\
\text { Fiber-covered } \\
\text { trunk with stiff } \\
\text { spines. Good } \\
\text { drainage essential. }\end{array}$ \\
\hline $\begin{array}{l}\text { Washingtonia } \\
\text { filifera }\end{array}$ & $\begin{array}{l}\text { California } \\
\text { Washington } \\
\text { palm }\end{array}$ & $\begin{array}{l}\text { California, } \\
\text { Mexico }\end{array}$ & $\begin{array}{l}\text { Desert } \\
\text { regions }\end{array}$ & $\begin{array}{l}8 \mathrm{a}-11 \\
12^{\circ} \mathrm{F}\end{array}$ & $50^{\prime}$ & Moderate & Solitary & Full sun & Moderate & $\begin{array}{l}\text { Costa- } \\
\text { palmate }\end{array}$ & $\begin{array}{l}\text { Grayish- } \\
\text { green }\end{array}$ & $\begin{array}{l}\text { Requires } \\
\text { well-drained soil. } \\
\text { Larger diameter } \\
\text { trunk than } W \text {. } \\
\text { robusta. Hybridizes } \\
\text { with } W \text {. robusta. }\end{array}$ \\
\hline $\begin{array}{l}\text { Washingtonia } \\
\text { robusta }\end{array}$ & $\begin{array}{l}\text { Washington } \\
\text { palm }\end{array}$ & Mexico & $\begin{array}{l}\text { Desert } \\
\text { regions }\end{array}$ & $\begin{array}{l}9 a-11 \\
22^{\circ} \mathrm{F}\end{array}$ & $\begin{array}{l}70- \\
100^{\prime} ; 25^{\prime} \\
\text { in } \\
\text { northern } \\
\text { FL }\end{array}$ & Fast & Solitary & Full sun & Moderate & $\begin{array}{l}\text { Costa- } \\
\text { palmate }\end{array}$ & $\begin{array}{l}\text { Bright } \\
\text { green }\end{array}$ & $\begin{array}{l}\text { Though from } \\
\text { desert regions, } \\
\text { fastest growth } \\
\text { occurs with regular } \\
\text { irrigation. Requires } \\
\text { well-drained soil. }\end{array}$ \\
\hline
\end{tabular}


Table 1. Palms for northern Florida and their associated characteristics ${ }^{3}$.

\begin{tabular}{|c|c|c|c|c|c|c|c|c|c|c|c|c|}
\hline $\begin{array}{l}\text { Scientific } \\
\text { Name }\end{array}$ & $\begin{array}{l}\text { Common } \\
\text { Name }\end{array}$ & Origin & $\begin{array}{l}\text { Native } \\
\text { Habitat }\end{array}$ & \begin{tabular}{|l|} 
Hardines \\
s Zone
\end{tabular} & $\begin{array}{l}\text { Typical } \\
\text { Height }\end{array}$ & $\begin{array}{l}\text { Growth } \\
\text { Rate } \\
\end{array}$ & Habit & Light & \begin{tabular}{l|} 
Salt \\
Tolerance \\
\end{tabular} & $\begin{array}{l}\text { Leaf } \\
\text { Type }\end{array}$ & $\begin{array}{l}\text { Foliage } \\
\text { Color }\end{array}$ & Comments \\
\hline \multicolumn{13}{|c|}{$\begin{array}{l}{ }^{3} \text { Non-native palms found in Florida s natural areas are indicated, with footnotes stating their status as established by the "IFAS Assessment of the Status of Non-native Plants in } \\
\text { Florida s Natural Areas" (Fox et al. 2005). Non-native palms without footnotes have not been reported in Florida s natural areas and/or have not yet been assessed using the IFAS } \\
\text { Assessment. } \\
{ }^{4} \text { In north Florida this species is not considered a problem and may be recommended. In central Florida, this species can be used but it should be treated with caution and managed to } \\
\text { prevent its escape (counties are listed by zone at: http://plants.ifas.ufl.edu/assessment/pdfs/assess_counties.pdf). Note that other conclusions may apply in south Florida. } \\
\text { phes } \\
{ }^{5} \text { This species is not considered a problem in north and central Florida and may be recommended (counties are listed by zone at: } \\
\text { http://plants.ifas.ufl.edu/assessment/pdfs/assess_counties.pdf). Note that other conclusions may apply in south Florida. } \\
6 \text { This species is not considered a problem in north and central Florida and may be recommended (counties are listed by zone at: } \\
\text { http://plants.ifas.ufl.edu/assessment/pdfs/assess_counties.pdf). Note that other conclusions may apply in south Florida. } \\
\text { 7This species is not considered a problem in north and central Florida and may be recommended (counties are listed by zone at: } \\
\text { http://plants.ifas.ufl.edu/assessment/pdfs/assess_counties.pdf). Note that other conclusions may apply in south Florida. }\end{array}$} \\
\hline
\end{tabular}

